\title{
A EXPERIÊNCIA DA GRAVIDEZ: O CORPO GRÁVIDO, A RELAÇÃO COM A MÃE, A PERCEPÇÃO DE MUDANÇA E A RELAÇÃO COM O BEBÉ
}

\author{
Ana Meireles ${ }^{1}$ \\ Maria Emília Costa ${ }^{2}$
}

Resumo: Apresenta-se um estudo de exploração da experiência da gravidez que utiliza o Maternal-Fetal Attachment Scale de Cranley (1981) para avaliar a relação mãe-bebé, e o Questionário de Avaliação da vivência da Gravidez (Meireles \& Costa, 2004) para avaliar a vivência do corpo grávido, a relação com a própria mãe e a percepção de mudança pessoal com a gravidez. Os resultados obtidos com uma amostra de 329 grávidas foram tratados em termos das diferenças quanto ao trimestre de gravidez, à paridade, ao estado civil, ao planeamento da gravidez e ao apoio social. Testou-se ainda a associação entre a relação mãe-bebé e a vivência da gravidez, encontrando-se uma correlação muito significativa entre estas dimensões, em que se destacam os valores obtidos em relação à vivência do corpo grávido, o que é discutido em termos do papel da vivência corporal na construção da identidade materna e na construção da relação mãe-bebé na gravidez, enfatizando-se as suas potencialidades em termos da intervenção psicológica.

Palavras-chave: Gravidez, relação mãe-bebé, corpo grávido, desenvolvimento da identidade materna.

The experience of pregnancy: The pregnant body, the relationship with woman's own mother, the perception of change and the mother-child relationship (Abstract): This paper presents a study of exploration of the experience of the pregnancy, as a contribution to the understanding of the body experience's role in the significant relationships that adults establish and their psychological development. So we evaluate the perception of personal change, the relationship with the own mother and the relationship with the baby in the pregnancy, besides the evaluation of the experience of the pregnant body. For that, the Maternal-Fetal Attachment Scale (MFA - Cranley et al., 1981-1993) and a new pregnancy questionnaire (QAG Questionário de Avaliação da Vivência da Gravidez) were used with 329 pregnant women in the three different pregnancy stages, evaluating their relationship with

\footnotetext{
${ }^{1}$ Aluna de Doutoramento da Faculdade de Psicologia e de Ciências da Educação da Universidade do Porto e bolseira da Fundação para a Ciência e a Tecnologia do Ministério da Ciência e do Ensino Superior (SFRH/ BD/ 1392/ 2000).

2 Professora Associada com Agregação na Faculdade de Psicologia e de Ciências da Educação da Universidade do Porto.
} 
the unborn baby, the experience of the pregnant body, the relationship with their own mother and their perception of personal change with the pregnancy. The QAG and the MFA were tested according to the pregnancy stages, the parity, the marital status, the pregnancy planning and the social support. The association among the mother-baby relationship and the experience of the pregnancy was also tested, finding a very significant correlation among these dimensions, standing out the values obtained for the experience of the pregnant body. These results are discussed considering the body experience role in relation to identity development in the processes of the acquisition of the maternal role, and of the construction of the mother-child relationship during pregnancy, being emphasized their potentialities for the psychological intervention.

\section{Introdução}

\section{A gravidez como transição desenvolvimental}

Numa perspectiva desenvolvimental, é consensual que, ao longo do ciclo de vida, as pessoas encontram numerosos períodos de transição que envolvem a actualização do autoconceito e das relações com os outros significativos (Ruble et al., 1990; Cohen \& Slade, 2000; Canavarro, 2001). A gravidez e a maternidade são normalmente descritas como uma das tarefas desenvolvimentais mais significativas da idade adulta. De facto, a gravidez - especialmente a primeira, envolve uma reorganização a todos os níveis: biológico, cognitivo, emocional, relacional e social, transformando a relação da mulher com o seu corpo, o seu self, as suas figuras significativas e a sua comunidade, constituindo-se assim como uma transição desenvolvimental.

Tarefas psicológicas da gravidez: identidade materna e relação mãe-bebé

Como etapa desenvolvimental, a gravidez supõe a resolução de tarefas psicológicas específicas: a construção da identidade materna e a construção da relação mãe-bebé, em torno das quais se processa, então, a redefinição psicossocial própria desta transição.

\section{A construção da identidade materna}

Ao longo da gravidez, a mulher tem que passar a ver-se como mãe. A construção da identidade materna envolve a referência à relação da grávida com a sua mãe: "a própria mãe é para cada mulher o primeiro e principal modelo de comportamentos e afectos maternos" (Canavarro, 2001, 
p. 26). Mas, mais do que um processo de simples reprodução de um modelo materno, ocorre uma verdadeira reavaliação desta relação durante a grãvidez, que permite adoptar alguns comportamentos semelhantes aos da mãe que considere adequados e outros comportamentos diferentes em substituição dos que considera disfuncionais, ou pouco adaptados à sua situação pessoal, construindo assim a sua própria identidade materna (Canavarro, 2001).

\section{A construção da relação com o bebé}

Entrelaçada com o processo de reconstrução das relações de vinculação precoces e de construção da identidade materna está a tarefa de estabelecer uma ligação afectiva com o bebé (Condon \& Corklindale, 1997). O estudo da relação mãe-bebé tem-se focado especialmente no seu impacto no desenvolvimento do bebé, mas não podemos esquecer as mudanças experienciadas pela mulher no desempenho do papel de mãe. Efectivamente, esta relação é crítica para a qualidade do desenvolvimento da criança, mas não deixa, por isso, de ter um papel incontornável no funcionamento e desenvolvimento psicológico da própria mãe. A perspectiva de responsabilidade perante um filho pode ter um forte impacto na mulher que, terá que aprender a relacionar-se com um bebé, disponibilizando uma grande parte do seu investimento emocional para assegurar a segurança e o bem-estar de um novo ser, que passará a depender de si. A construção desta ligação afectiva inicia-se muito antes do nascimento, numa adaptação corporal, emocional e cognitiva ao bebé em desenvolvimento, constituindo uma tarefa psicológica essencial da gravidez (Cranley, 1981; Colman \& Colman, 1994; Condon \& Corklindale, 1997; Mendes, 2002).

\section{A vivência do corpo na gravidez}

$\mathrm{Na}$ resolução destas duas tarefas (identidade materna e relação com o bebé), tem um papel fundamental a vivência do corpo e das transformações físicas da gravidez, pois confronta a mulher com a existência do bebé e com o seu novo papel de mãe: o seu corpo passou a conter outra pessoa. Esta consciência da presença do bebé vai sendo cada vez mais forte: os chamados "pontapés" (movimentos fetais) são o momento de contacto com o bebé como um ser vivo e é dos acontecimentos mais significativos da gravidez (Lee, 1995). Esta realidade física prepara a mulher grávida para mudanças profundas na sua realidade psicológica. Aliás, a percepção dos movimentos fetais tem sido consistentemente relacionada com a construção da representação do bebé e da ligação emocional ao bebé (Siddiqui, Haeggloef \& Eisemann, 1999). De resto, foi já possível confirmar esta 
relação entre a vivência do corpo e a construção da relação mãe-bebé numa análise prévia dos resultados obtidos (Meireles \& Costa, 2004).

No estudo da influência da vivência corporal no desenvolvimento da identidade do adulto, é, assim, possível destacar a gravidez como um acontecimento de vida que reúne claramente os dois níveis de mudança psicológica, pois (a) ao nível da vivência corporal, são óbvias as drásticas mudanças e experiências corporais e, (b) ao nível do processo de desenvolvimento da identidade, é evidente o forte desafio que é colocado pelo novo papel. No entanto, a revisão da literatura permitiu constatar as limitações existentes em termos da investigação desenvolvida, no sentido de associar o corpo enquanto objecto de estudo da psicologia com as variáveis relacionadas com a gravidez. Assim, considera-se pertinente a compreensão da relação da grávida com o seu corpo na avaliação da vivência da gravidez. Esta proposta de exploração da experiência da gravidez tem como objectivo contribuir para a compreensão da vivência do corpo no adulto, e sua importância nas relações significativas que estabelece e que são o palco do seu desenvolvimento psicológico.

\section{Outros factores da vivência da gravidez}

A forma como o indivíduo lida com a transição está, no entanto, sujeita a diversos constrangimentos que têm que ver não só com as próprias características do indivíduo e do acontecimento, mas, também, com as características do seu contexto de vida.

Contexto relacional diádico, relação com a mãe e percepção de apoio social

A vivência da gravidez é fortemente influenciada pelo contexto social da mulher, em que se destaca a sua relação com o companheiro e com a família de origem. De facto, a disponibilidade do apoio social - do companheiro e dos outros elementos da rede social mais alargada - mostrou-se essencial na qualidade da adaptação à gravidez (Condon \& Corklindale, 1997; Smith, 1999), pelo que foi introduzida a avaliação da percepção do apoio social como variável incontornável na compreensão da vivência da gravidez (e da adaptação a qualquer transição, em geral). De entre as variáveis relacionais a ter em conta na compreensão da vivência da gravidez, destacamos, no presente trabalho, além do apoio social, o contexto conjugal em que a gravidez se enquadra (estado civil) e a avaliação da relação com a própria mãe. 


\section{Características da gravidez}

Nas características associadas à gravidez que se espera condicionem também a forma como a mulher grávida lida e resolve esta transição, destacamos o facto de ser a primeira gravidez, pois é o acontecimento que precipita a transição para a maternidade e em que o principal processo de mudança ocorre com as grandes alterações na vida pessoal, relacional, familiar, profissional e social. Outros factores relativos à gravidez, incontornáveis, na compreensão da forma como a mulher grávida experiencia esta transição, que muito condicionam o significado que este acontecimento assumirá para a futura mãe, são necessariamente o facto de a gravidez ter sido planeada e ser desejada (Fischer, Stanford, Jameson \& Dewitt, 1999). Associada a esta dimensão estará ainda a dificuldade em engravidar como uma variável que exacerbará todo o desejo de gravidez e o seu planeamento, imprimindo à vivência de uma gravidez nestas condições uma dinâmica emocional própria. Da mesma forma, é importante ter ainda em conta a presença de complicações médicas associadas à gravidez, o que condicionará também a vivência desta experiência, envolvendo um grau de ansiedade acrescido, mas também uma antecipação e uma intensificação de muitas das preocupações (como a preocupação com o bem-estar do bebé) que, sendo próprias de qualquer gravidez, assumem, nestes casos, um significado e uma dinâmica emocional particulares.

\section{O decurso do processo gravídico}

Todos estes factores que condicionam a vivência da gravidez são "jogados" e reconstruídos ao longo do processo gravídico, reenquadrados em diferentes configurações psicológicas, numa dinâmica desenvolvimental que deverá confluir para a resolução idiossincrática das tarefas psicológicas da gravidez. Assim, é esperado que, ao longo da gravidez, vão sendo progressivamente construídas a identidade materna e a relação com o bebé na confluência de todos estes condicionantes.

\section{Metodologia}

\section{Hipóteses de Investigação}

É no seguimento deste conjunto de objectivos e pressupostos que estabelecemos como hipóteses de trabalho:

H1. A vivência da gravidez e a relação com o bebé variam com o tempo de gravidez (trimestre de gravidez); 
H2. A vivência da gravidez e a relação com o bebé variam em função de variáveis relacionais e sociais (estado civil, relação com a mãe, percepção de apoio social);

H3. A vivência da gravidez e a relação com o bebé variam em função de variáveis obstétricas (paridade, planeamento da gravidez, gravidez desejada, dificuldade em engravidar, gravidez de risco);

H4. A relação com o bebé varia em função da vivência da gravidez (vivência do corpo grávido, relação com a mãe, mudança pessoal com a gravidez).

\section{Participantes}

Para explorar as hipóteses levantadas, recorreu-se à consulta externa de serviços públicos de obstetrícia, envolvendo um total de 364 grávidas que constituem a nossa amostra. Neste estudo, não foram consideradas as grávidas adolescentes (com idade inferior a 20 anos), por se entender que este grupo apresenta especificidades desenvolvimentais, psicossociais e contextuais que imprimem à vivência da gravidez e à relação com o bebé, bem como ao seu contexto de vida, uma dinâmica muito particular que não cabe a este trabalho abordar. Assim, foram considerados os valores referentes a 329 participantes, distribuídas de forma homogénea pelos três trimestres de gravidez. Na sua maioria têm entre 21 e 35 anos de idade $(85,4 \%, M=28,6, \mathrm{SD}=5,2)$, são casadas ou vivem em união de facto $(94,8 \%)$ e são primíparas (51,4\%). $18,5 \%$ das gravidezes não foram planeadas, mas apenas $0,6 \%$ das grávidas reagiram negativamente à notícia da gravidez. $85,4 \%$ das gravidezes não apresentavam qualquer complicação médica ou risco para o bebé ou a mãe. Em termos de grau de escolaridade, $64,4 \%$ das grávidas participantes não tinha o $9 .^{\circ}$ ano e, relativamente à situação profissional, $18,2 \%$ estavam desempregadas no momento da recolha de dados.

\section{Procedimento de recolha e análise dos dados}

Os questionários foram administrados por uma psicóloga em contexto hospitalar urbano, no Serviço de Consulta Externa - Obstetrícia, em articulação com o Pessoal Médico e de Enfermagem envolvido, que encaminhou individualmente para o espaço localmente organizado para o efeito, com condições de privacidade e conforto, as grávidas que voluntariamente se disponibilizassem para colaborar, depois de apresentados o enquadramento institucional e os objectivos gerais da investigação. 
Os dados foram depois tratados utilizando-se a estatística paramétrica do programa SPSS (Statistical Package for Social Sciences). Os dados referentes à caracterização da amostra foram analisados em termos de distribuição de frequências e percentagens. Para testar as hipóteses levantadas, recorremos à análise da variância (ANOVA) e à análise de correlações (coeficiente de correlação de Pearson).

\section{Instrumentos}

\section{Questionário de Avaliação da Vivência da Gravidez}

O Questionário de Avaliação da vivência da Gravidez (Meireles \& Costa, 2004) avalia a vivência do corpo grávido, a relação com a mãe e a gravidez como factor de mudança pessoal, num total de 22 itens $^{3}$. O factor 1 ("Vivência do Corpo Grávido") é atravessado por conteúdos associados a uma vivência positiva do corpo na gravidez que remetem para uma identificação com a gravidez e a maternidade ("gosto de me ver com o corpo de grávida"), com um alpha de 0,86; o factor 2 ("Relação com a Mãe"), com um alpha de 0,87 , remete esta avaliação para um laço emocional profundo com raízes no passado ("a minha mãe fazia-me mimos"), com apenas um item reportando-se a uma mudança nesta relação ("desde que estou grávida, compreendo melhor a minha mãe "), no sentido de uma maior cumplicidade e identificação com a própria mãe; o factor 3 ("Mudança Pessoal com a Gravidez"), com um alpha de 0,85, aborda a percepção do impacto da gravidez e da maternidade na vida da mulher ("este bebé vai alterar a minha vida").

\section{Maternal-Fetal Attachment Scale}

Desenvolvido por Mecca S. Cranley (1981), a versão original deste instrumento de avaliação da qualidade da relação afectiva da mãe com o feto (com um alpha global de 0,84 ) é constituída por 24 itens com resposta tipo Likert, organizados em cinco dimensões ${ }^{4}$. Este instrumento tem sido utilizado especialmente no $2 .^{\circ}$ e $3 .^{\circ}$ trimestres de gravidez (Heidrich \& Cranley, 1989; Grace, 1989; Cranley, 1993; Mendes, 2002), pelo que houve a necessidade de o adaptar ao presente estudo, excluindo-se os itens específicos do $2 .^{\circ}$ e $3 .^{\circ}$ trimestres (como, por exemplo, "gosto de ver a

\footnotetext{
${ }^{3}$ Este novo instrumento foi construído com base em dois instrumentos já existentes: a "Escala de Avaliação da Gravidez e Maternidade" de Xavier (2000), e o "Childbearing Attitudes Questionnaire" de Ruble e colaboradores (1990), tendo sido ainda acrescentados novos itens que pudessem fortalecer a avaliação das dimensões.

${ }^{4}$ As cinco dimensões psicológicas em que Cranley (1981) organiza a versão original do MFA são: Construção do Papel Materno (“Role-taking”), Diferenciação do Self em relação ao Feto, Interacção com o Feto, Atribuição de Características ao Feto e Partilha do Self.
} 
barriga a mexer quando o bebé dá pontapés"), tendo-se utilizado uma versão reduzida do instrumento, preparada expressamente para a avaliação da relação mãe-bebé nos três trimestres de gravidez, com 15 itens que se organizaram em dois factores. O factor 1 ("Envolvimento Emocional com o Bebé") com um alpha de 0,79 está muito relacionado com a interacção actual com o bebé ("converso com o meu bebé") e com o investimento emocional na gravidez ("tenho deixado de fazer certas coisas para o bebé ser saudável"), destacando-se a dimensão presente da relação mãe-bebé in utero. O factor 2 ("Construção da Identidade Materna") com um alpha de 0,78 reúne itens mais centrados na interacção com o bebé no futuro e na antecipação do papel de mãe ("imagino-me a cuidar do meu bebé"). A distribuição dos itens por estes dois factores vai ao encontro dos pressupostos teóricos apresentados, ao enfatizar tanto a construção do papel de mãe, como a interacção com o bebé na gravidez.

\section{Resultados}

\section{Análise de Diferenças}

Os resultados obtidos com o QAG e o MFA foram tratados em termos da análise de diferenças, tal como se apresentam no quadro 1.

Diferenças entre os trimestres de gravidez

\section{$Q A G$}

Em relação à avaliação da vivência da gravidez (QAG) e comparando as médias obtidas pelas grávidas dos três trimestres (cf. quadro 1), não se encontraram, à partida, diferenças estatisticamente significativas. No entanto, verificamos que tanto no factor 1 ("Vivência do Corpo Grávido") como no factor 3 ("Mudança Pessoal com a Gravidez") parecia haver uma quebra mais acentuada entre o $1 .^{\circ}$ e o $2 .^{\circ}$ trimestres, estabilizando depois no $3^{\circ}$ trimestre, pelo que fomos comparar estes dois grupos de grávidas $\left(1 .^{\circ}\right.$ vs. $2 .^{\circ}$ e $3 .^{\circ}$ trimestres) quanto a estes factores, encontrando efectivamente uma diferença com significado estatístico para o $1 .^{\circ}$ factor, relativo à "Vivência do Corpo Grávido" $(\mathrm{p}=0,048)$ o que poderá sugerir que é entre o $1 .^{\circ}$ e o $2 .^{\circ}$ trimestres que se verifica a principal mudança neste factor. No entanto, este efeito terá que ser confirmado em estudos futuros.

\section{$M F A$}

Quanto aos valores obtidos no MFA, e tal como esperado, as médias relativas aos trimestres de gravidez (quadro 1) mostram que as mulheres na fase final da sua gravidez apresentam valores mais elevados de Relação 
Mãe-Bebé. Mas, apesar das médias obtidas nos factores aumentar de uma forma geral com o trimestre de gravidez, estas diferenças de média apenas são significativas $(\mathrm{p}=0,036)$ no factor 1 ("Envolvimento Emocional com o Bebé"), nomeadamente entre as grávidas do $1 .^{\circ}$ e do $3 .^{\circ}$ trimestres.

Assim, podemos verificar que, de um modo geral, as médias tendem a aumentar com o trimestre de gravidez. Este aumento parece ser mais contínuo, gradual e progressivo, nas dimensões da relação com o bebé (MFA) ao longo da gravidez, e mais "brusco" nas dimensões da vivência da gravidez (QAG) que parecem ter uma diferença de médias com maior amplitude entre o $1 .^{\circ}$ e o $2 .^{\circ}$ trimestres, estabilizando depois entre o $2 .^{\circ}$ e o 3..$^{\circ}$ trimestres. Assim, em relação ao MFA, estaremos perante uma dimensão com um desenvolvimento que parece ocorrer ao longo de toda a gravidez. Em relação ao QAG, parece ser entre o $1 .^{\circ}$ e o $2 .^{\circ}$ trimestres que se verifica a principal mudança no factor "Vivência do Corpo Grávido", o que poderá ser explicado pelas profundas transformações corporais do 2. ${ }^{\circ}$ trimestre. De qualquer forma, estas mudanças no QAG não parecem ser muito significativas, o que poderá indicar que a vivência da gravidez estará mais relacionada com as condições em que este acontecimento de vida se enquadra (e que, em larga medida, a precedem) e menos com o decorrer da própria gravidez. No entanto, apesar destes resultados poderem sugerir que estas dimensões mudam ao longo da gravidez, só com um design longitudinal intra-sujeito se poderá concluir sobre a sua estabilidade / mudança.

Quadro 1: Diferenças na Vivência da Gravidez (QAG) e na Relação Mãe-Bebé (MFA)

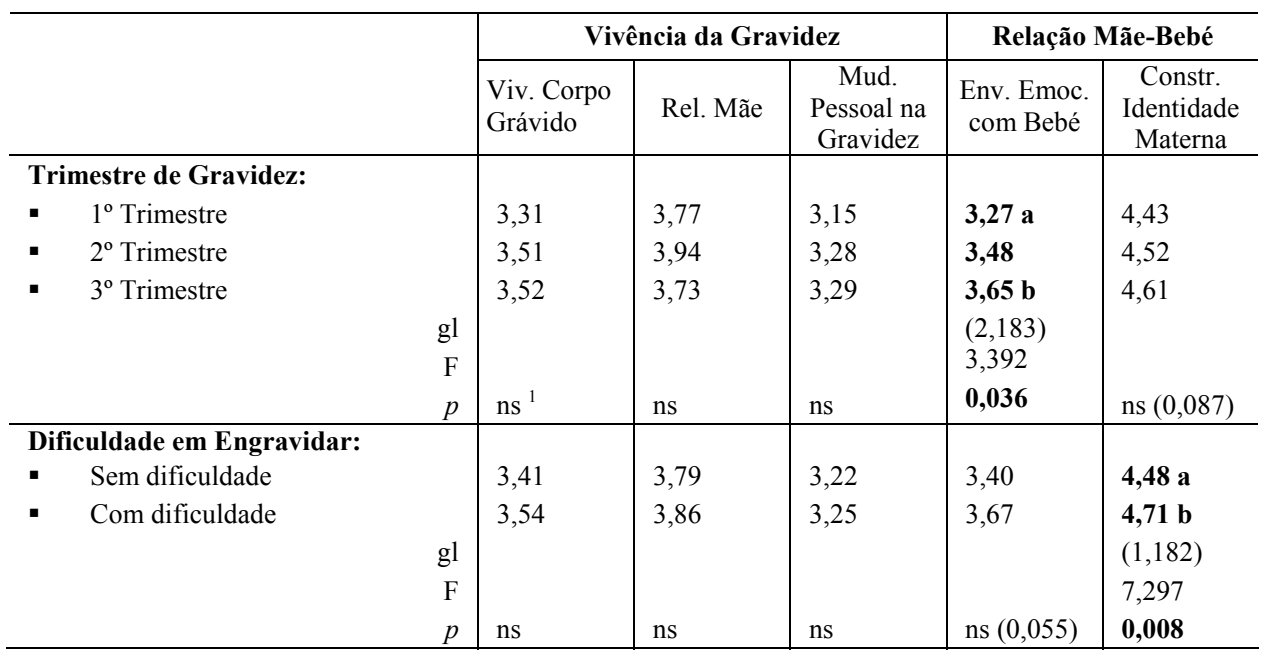

(continua) 
(continuação)

\begin{tabular}{|c|c|c|c|c|c|c|}
\hline & & \multicolumn{3}{|c|}{ Vivência da Gravidez } & \multicolumn{2}{|c|}{ Relação Mãe-Bebé } \\
\hline & & $\begin{array}{l}\text { Viv. Corpo } \\
\text { Grávido }\end{array}$ & Rel. Mãe & $\begin{array}{c}\text { Mud. } \\
\text { Pessoal na } \\
\text { Gravidez }\end{array}$ & $\begin{array}{c}\text { Env. Emoc. } \\
\text { com Bebé }\end{array}$ & $\begin{array}{c}\text { Constr. } \\
\text { Identidade } \\
\text { Materna } \\
\end{array}$ \\
\hline $\begin{array}{l}\text { Estado Civil: } \\
\text { - } \quad \text { Casada ou em União de facto } \\
\text { - } \quad \text { Solteira }\end{array}$ & $\begin{array}{l}\mathrm{gl} \\
\mathrm{F}\end{array}$ & $\begin{array}{l}3,45 \\
3,24 \\
\text { ns }\end{array}$ & $\begin{array}{l}3,82 \\
3,50 \\
\\
\text { ns }\end{array}$ & $\begin{array}{l}\mathbf{3 , 2 0} \mathbf{a} \\
\mathbf{3 , 7 8} \mathbf{b} \\
(1,289) \\
3,927 \\
\mathbf{0 , 0 4 8}\end{array}$ & $\begin{array}{l}3,45 \\
3,67\end{array}$ & $\begin{array}{l}4,54 \\
4,38\end{array}$ \\
\hline $\begin{array}{l}\text { Gravidez Planeada: } \\
\text { - } \quad \text { Sim ou Mais ou Menos } \\
\text { - Não }\end{array}$ & $\begin{array}{l}\mathrm{gl} \\
\mathrm{F} \\
p\end{array}$ & $\begin{array}{l}\mathbf{3 , 5 1} \mathbf{a} \\
\mathbf{3 , 1 5} \mathbf{b} \\
(1,290) \\
7,918 \\
\mathbf{0 , 0 0 5}\end{array}$ & $\begin{array}{l}\mathbf{3 , 8 8} \mathbf{a} \\
\mathbf{3 , 5 6} \mathbf{b} \\
(1,290) \\
4,784 \\
\mathbf{0 , 0 3 0}\end{array}$ & $\begin{array}{l}3,18 \\
3,46 \\
\text { ns }(0,064)\end{array}$ & $\begin{array}{l}3,46 \\
3,49\end{array}$ & $\begin{array}{l}4,55 \\
4,45 \\
\\
\text { ns }\end{array}$ \\
\hline $\begin{array}{ll}\text { Reacção à Gravidez: Feliz } \\
\text { - } & \text { Muito Feliz } \\
\text { - } & \text { Bastante Feliz } \\
\text { - } & \text { Um Pouco Feliz } \\
\text { - } & \text { Nada Feliz }\end{array}$ & $\begin{array}{l}\mathrm{gl} \\
\mathrm{F} \\
p\end{array}$ & $\begin{array}{l}\mathbf{3 , 5 5} \text { a } \\
\mathbf{3 , 3 0} \\
\mathbf{3 , 1 4} \\
\mathbf{2 , 9 0} \mathbf{b} \\
(3,290) \\
4,790 \\
\mathbf{0 , 0 0 3}\end{array}$ & $\begin{array}{l}\mathbf{3 , 9 5} \text { a } \\
\mathbf{3 , 6 6} \\
\mathbf{3 , 0 9} \text { b } \\
\mathbf{3 , 3 1} \\
(3,290) \\
6,667 \\
\mathbf{0 , 0 0 0}\end{array}$ & $\begin{array}{l}3,20 \\
3,18 \\
3,33 \\
3,71\end{array}$ & $\begin{array}{l}3,55 \\
3,29 \\
3,56 \\
3,09\end{array}$ & $\begin{array}{l}4,56 \\
4,52 \\
4,35 \\
4,38\end{array}$ \\
\hline $\begin{array}{ll}\text { Reacção à Gravidez: Preocupada } \\
\text { - } & \text { Muito Preocupada } \\
\text { - } & \text { Bastante Preocupada } \\
\text { - } & \text { Um Pouco Preocupada } \\
\text { - } & \text { Nada Preocupada } \\
& \\
\end{array}$ & $\begin{array}{l}\mathrm{gl} \\
\mathrm{F} \\
p\end{array}$ & $\begin{array}{l}\mathbf{3 , 0 1} \mathbf{a} \\
\mathbf{3 , 0 3} \\
\mathbf{3 , 3 6} \\
\mathbf{3 , 6 2} \mathbf{b} \\
(3,290) \\
5,200 \\
\mathbf{0 , 0 0 2}\end{array}$ & $\begin{array}{l}\mathbf{3 , 3 8} \mathbf{a} \\
\mathbf{3 , 7 3} \\
\mathbf{3 , 5 6} \\
\mathbf{3 , 9 8} \mathbf{b} \\
(3,290) \\
5,298 \\
\mathbf{0 , 0 0 1}\end{array}$ & $\begin{array}{l}\mathbf{3 , 7 2} \text { a } \\
\mathbf{3 , 4 2} \\
\mathbf{3 , 3 2} \\
\mathbf{3 , 1 0} \text { b } \\
(3,289) \\
4,243 \\
\mathbf{0 , 0 0 6}\end{array}$ & $\begin{array}{l}3,34 \\
3,27 \\
3,52 \\
3,51 \\
\\
\text { ns }\end{array}$ & $\begin{array}{l}\mathbf{4 , 5 1} \\
\mathbf{4 , 2 5} \text { b } \\
\mathbf{4 , 3 9} \text { b } \\
\mathbf{4 , 6 4} \text { a } \\
(3,182) \\
5,607 \\
\mathbf{0 , 0 0 1}\end{array}$ \\
\hline $\begin{array}{l}\text { Paridade: } \\
\text { - } \quad \text { Primípara } \\
\text { - } \quad \text { Multípara }\end{array}$ & $\begin{array}{r}\mathrm{gl} \\
\mathrm{F} \\
p\end{array}$ & $\begin{array}{l}\mathbf{3 , 5 7} \mathbf{a} \\
\mathbf{3 , 3 1} \mathbf{b} \\
(1,292) \\
6,624 \\
\mathbf{0 , 0 1 1}\end{array}$ & $\begin{array}{l}3,88 \\
3,73 \\
\\
\text { ns }\end{array}$ & $\begin{array}{l}\mathbf{3 , 4 7} \mathbf{a} \\
\mathbf{2 , 9 9} \mathbf{b} \\
(1,291) \\
16,703 \\
\mathbf{0 , 0 0 0}\end{array}$ & $\begin{array}{l}\mathbf{3 , 6 2} \text { a } \\
\mathbf{3 , 1 9} \mathbf{b} \\
(1,184) \\
12,808 \\
\mathbf{0 , 0 0 0}\end{array}$ & $\begin{array}{l}4,61 \text { a } \\
\mathbf{4 , 3 9} \text { b } \\
(1,184) \\
8,941 \\
\mathbf{0 , 0 0 3}\end{array}$ \\
\hline $\begin{array}{l}\text { Gravidez de Risco: } \\
\text { - } \quad \text { Sem risco } \\
\text { - } \quad \text { Com risco }\end{array}$ & $\begin{array}{l}\mathrm{gl} \\
\mathrm{F} \\
p\end{array}$ & $\begin{array}{l}3,42 \\
3,59 \\
\text { ns }\end{array}$ & $\begin{array}{l}3,84 \\
3,63 \\
\\
\text { ns }\end{array}$ & $\begin{array}{l}\mathbf{3 , 1 8} \\
\mathbf{3 , 5 8} \\
(1,285) \\
5,255 \\
\mathbf{0 , 0 2 3}\end{array}$ & $\begin{array}{l}3,44 \\
3,55\end{array}$ & $\begin{array}{l}4,51 \\
4,70\end{array}$ \\
\hline
\end{tabular}

(continua) 
(continuação)

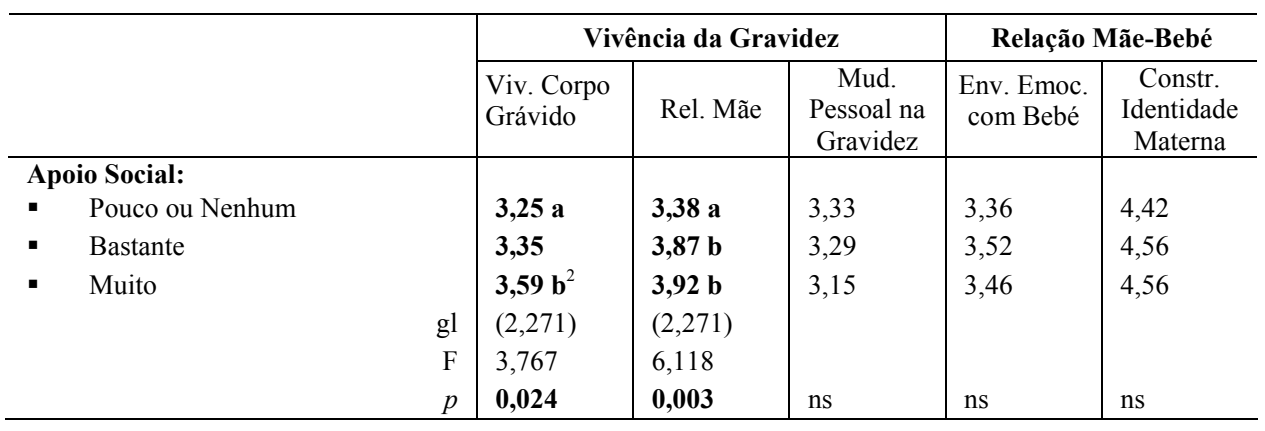

\footnotetext{
${ }^{1}$ Comparando só o $1 .{ }^{\circ}$ com o $2 .^{\circ}$ e $3 .^{\circ}$ trimestre, a diferença é significativa a $0,048(\mathrm{~F}(1,292)=3,952)$.

${ }^{2}$ Nesta análise do sentido das diferenças substituiu-se o teste de Scheffe (usado nas restantes análises) pelo teste de "Tukey's HSD" que é considerado menos exigente, mas que nos permitiu aceder aos respectivos valores post hocs.
}

Diferenças quanto à dificuldade em engravidar

Se os resultados relativos ao trimestre de gravidez parecem poder sugerir que a relação com o bebé evolui ao longo da gravidez, as diferenças encontradas entre as grávidas que tiveram dificuldade em engravidar e as que não tiveram (com médias mais elevadas para as grávidas com dificuldade em engravidar - cf. quadro 1) poderão até indicar que o processo de desenvolvimento da relação mãe-bebé tem início ainda mais cedo, anterior à própria concepção, associado a todo o investimento (emocional e comportamental) para conseguir a gravidez. As mulheres que tiveram que esperar e/ou esforçar-se por engravidar puderam iniciar o processo de se imaginarem como grávidas e como mães e de imaginarem os seus bebés ainda antes da própria concepção / gravidez ocorrer.

Uma outra explicação para estes resultados poderá ser que estas grávidas que esperaram por esta gravidez estão mais "prontas", mais "disponíveis" para se envolverem em todo o processo gravídico, pois puderam preparar-se a si próprias e a toda a sua vida para o aparecimento do novo bebé. Assim, estas grávidas estariam menos preocupadas com outros aspectos das suas vidas, podendo centrar-se mais na própria gravidez.

Diferenças quanto ao estado civil:

Neste mesmo sentido apontam também as diferenças quanto ao estado civil observadas no factor "Mudança Pessoal com a Gravidez" $(\mathrm{p}=0,002)$ entre as grávidas casadas $(\mathrm{M}=3,12)$ e as grávidas solteiras $(\mathrm{M}=3,78)$ que teriam questões adicionais para resolver, estando assim menos preparadas para esta transição. E, de facto, as grávidas casadas sen- 
tem significativamente menos a gravidez como factor de mudança pessoal do que as solteiras, que são as que apresentam médias mais elevadas neste factor. Este factor, que parece ter sido "lido" pelas participantes em termos do impacto (negativo) da gravidez nas suas vidas, é o que melhor distingue as grávidas quanto ao seu estado civil. Assim, o contexto conjugal em que se enquadra a gravidez é fundamental na percepção do impacto dessa gravidez na vida da grávida, e em toda a mudança pessoal que ela implicará necessariamente. Mesmo que a influência de um contexto conjugal desfavorável pareça ser minimizada em termos do seu impacto na qualidade da relação mãe-bebé e da experiência da gravidez (como parecem indicar os nossos dados, que não evidenciam diferenças significativas quanto a estes factores entre grávidas casadas e solteiras), isto acontecerá certamente com um maior custo para a mulher grávida, o que justifica as diferenças significativas encontradas nas grávidas solteiras na percepção de "Mudança Pessoal com a Gravidez". Portanto, a ausência de uma relação conjugal que enquadre a gravidez não está associada a diferenças significativas no envolvimento emocional com o bebé, nem na construção da identidade materna, nem na vivência do corpo grávido, mas isto poderá ter um custo pessoal acrescido, o que se reflecte no valor significativamente mais elevado obtido por estas grávidas (solteiras) no factor "Mudança Pessoal com a Gravidez".

\section{Diferenças quanto ao planeamento da gravidez e quanto à reacção} inicial à gravidez

\section{Gravidez Planeada}

Se compararmos as grávidas que referem não ter planeado esta gravidez com as outras, encontramos diferenças significativas relativas à "Vivência do Corpo Grávido" $(\mathrm{p}=0,005)$ e à "Relação com a Mãe" $(\mathrm{p}=0,030)$, em que as grávidas que não planearam a sua gravidez apresentam uma relação com o corpo grávido e com a mãe com valores mais baixos que as participantes que referem ter planeado a sua gravidez. Este efeito é mais evidente em relação à dimensão da "Vivência do Corpo Grávido", que parece estar, assim, fortemente associado ao desejo da gravidez.

Importa aqui ressalvar a distinção entre estes dois conceitos, pois um construto muito associado ao "planeamento da gravidez" mas que não se poderá confundir com ele é o "desejo da gravidez" (Fischer et al., 1999). Apesar da óbvia influência do planeamento de uma gravidez na forma como esta é recebida e depois conduzida, o conceito de gravidez desejada, de cariz mais emocional e eventualmente mais inconsciente (que poderá estar ou não em concordância com o conceito mais cognitivo e comporta- 
mental de gravidez planeada), é muitas vezes mais difícil de verbalizar e explicar, bem como de aceder em termos de avaliação psicológica.

Foi, pois, para aceder a este construto da gravidez desejada que foi incluída uma questão relativa à forma como a grávida reagiu à notícia da gravidez, quer em termos de se ter sentido "feliz", quer em termos de se ter sentido "preocupada", como forma de tentar contornar as óbvias dificuldades na avaliação deste construto, que se colocam não só em termos de desejabilidade social, mas, acima de tudo, em termos de protecção do sentido de coerência pessoal, pois poderá ser sentido como paradoxal (e até ameaçador) perguntar a uma mulher com uma gravidez em curso se esta gravidez foi / é ou não desejada. É que, mesmo que a gravidez não tenha sido desejada inicialmente, a mulher confrontou-se já com a "tarefa de a aceitar" (Colman \& Colman, 1994) que resultou num compromisso pessoal e profundo com o bem-estar do novo ser. Este processo de aceitação poderá não ser nada fácil e envolve sempre um certo grau de ambivalência emocional, mas, nos casos em que é conseguido (situação em que se encontra a nossa amostra, dado o contexto de acompanhamento obstétrico hospitalar), resultará num processo de identificação e comprometimento pessoal com a gravidez. Foi com plena consciência da natureza melindrosa deste construto (particularmente neste contexto concreto da nossa amostra) que se optou por avaliar a "reacção inicial à notícia da gravidez", sem deixar de ter como finalidade a avaliação do construto "gravidez desejada".

Avaliando-se então a Reacção à Gravidez, quanto mais "feliz" com a notícia da gravidez, mais positiva a vivência do corpo grávido e com a mãe. Este efeito da reacção inicial à gravidez é particularmente evidente na dimensão da "Relação com a Mãe" $(p=0,000)$, tendo também significado estatístico na dimensão da "Vivência do Corpo Grávido" $(p=0,003)$.

As dimensões relativas à relação mãe-bebé (MFA) não parecem, no entanto, ser sensíveis a estas duas variáveis (Gravidez Planeada e Reacção Feliz à Gravidez). Talvez porque a relação com o bebé dependa mais de variáveis mais estruturais, como a relação com a própria mãe (Siddiqui, Haeggloef \& Eisemann, 2000) ou as estruturas de vinculação (Fonagy, Steele \& Steele, 1991). Faz sentido que a construção da relação mãe-bebé - tão importante em termos ontogenéticos e filogenéticos - não se faça depender de factores circunstanciais como o facto da gravidez ter sido planeada ou desejada. Não que estes factores não influenciem esse processo, mas a sua resolução ou a forma como a mulher vai lidar com essas circunstâncias depende mais de factores associados à sua estrutura psicossocial, como eventualmente o seu padrão de vinculação (Mikulincer \& Florian, 1999; Fonagy, Steele \& Steele, 1991) ou a sua relação com o corpo (Meireles \& Costa, 2004). 
Avaliando ainda a Reacção à Gravidez, as grávidas que referem ter encarado com "preocupação" a notícia da gravidez evidenciam valores mais elevados de percepção de "Mudança Pessoal" e valores mais baixos de "Vivência do Corpo Grávido", de "Relação com a Mãe" e de "Construção da Identidade Materna" do que as grávidas que não referem qualquer preocupação perante a notícia da gravidez.

Esta variável parece ser mais sensível às dimensões da vivência da gravidez e da relação com o bebé do que as variáveis anteriores, o que poderá significar que a preocupação com a notícia da gravidez não está tão sujeita à desejabilidade social como o referir ter ficado feliz com a notícia. É naturalmente mais "fácil" a uma mulher que, quer tenha ou não planeado/desejado, tem efectivamente uma gravidez em curso assumir que ficou "muito preocupada" com a notícia da gravidez, do que assumir que não ficou "nada feliz" com a notícia da gravidez. Assim, a preocupação perante a notícia da gravidez poderá constituir um bom indicador do facto de esta ter sido desejada. Até porque a eventual existência de outros motivos de preocupação independentes deste desejo da gravidez, como a presença de complicações médicas associadas, só surgem mais tarde e, em princípio, nada têm que ver com a reacção inicial à gravidez (e, de facto, as diferenças de médias mantêm-se significativas se filtrarmos as grávidas com risco obstétrico e efectuarmos a mesma análise de variância).

\section{Diferenças entre as grávidas primíparas e as grávidas multíparas}

\section{$Q A G$}

Em relação à paridade, as grávidas primíparas apresentam valores de vivência do corpo grávido significativamente mais elevados do que as outras grávidas, o que poderá estar associado ao impacto psicológico da primeira experiência de gravidez. E, de facto, as grávidas primíparas sentem significativamente mais a gravidez como mudança pessoal, o que vai ao encontro dos pressupostos teóricos apresentados, segundo os quais seria precisamente na primeira gravidez que a principal mudança na identidade da mulher ocorre, com a sua "entrada" na maternidade.

\section{$M F A$}

Os resultados obtidos no primeiro factor do MFA vão ao encontro dos valores obtidos com o QAG, na medida em que as primíparas apresentam valores mais elevados de "Envolvimento Emocional com o Bebé" $(\mathrm{p}=0,001)$ do que as participantes que já tinham estado grávidas.

Mas, um resultado de que não estávamos à espera era da diferença observada entre as primíparas e as outras grávidas quanto à "Construção da Identidade Materna". Pois, se, por um lado, esperássemos que as primípa- 
ras estivessem mais envolvidas com o bebé (pois é o seu primeiro filho, aquele que a transforma irreversivelmente em mãe), admitíamos, no entanto, que fosse mais difícil para estas mulheres, grávidas pela primeira vez, imaginar-se como mães: a construção do papel materno. Mas, pelo contrário, foram as primíparas que obtiveram médias mais elevadas naquele factor. Porquê? Uma possível explicação poderia ser que é precisamente por estas grávidas terem que esforçar-se mais para se imaginarem como mães e aos seus bebés. Assim, quando perguntamos a uma primípara se ela tenta imaginar como será o seu bebé e ela nos diz "sim, muito", possivelmente ela estará a referir-se, não tanto à facilidade que tem em fazê-lo, mas sim ao esforço e à energia que disponibiliza para o fazer. Uma multípara não precisa (e talvez nem possa!) gastar tanto tempo e energia a preparar-se para ser mãe e para aprender a relacionar-se com o bebé. É precisamente na $1 .^{a}$ gravidez que este processo de mudança psicológica ocorre, o que tem sido consistentemente referido por diferentes autores que se dedicam à compreensão desta transição (Ruble et al., 1990; Smith, 1999; Cohen \& Slade, 2000; Canavarro, 2001).

\section{Diferenças quanto ao Apoio Social}

Os resultados obtidos foram também testados quanto ao apoio social (quadro 1), revelando que os valores do $Q A G$ aumentam significativamente com o nível de apoio social no factor "Vivência do Corpo Grávido" $(p=0,024)$ e no factor "Relação com a Mãe" $(p=0,003)$. Assim, as grávidas que sentem mais apoio social apresentam médias significativamente mais elevadas tanto na dimensão da vivência do corpo grávido (que remete para a identificação com a gravidez), como na dimensão da relação com a mãe, o que indicia a provável importância desta relação para a percepção de apoio social na gravidez.

O processo de identificação com a gravidez (patente no factor "Vivência do Corpo Grávido") parece, assim, estar ligado à percepção de apoio social, permitindo induzir o papel "dos outros" no processo de construção do significado da gravidez (Smith, 1999). A maternidade desenvolve-se no contexto de uma família e do seu enquadramento sociocultural, pelo que a atitude da mulher face à gravidez depende em larga medida desse mesmo enquadramento. Estes dados enfatizam o papel da aceitação e do apoio por parte das figuras mais significativas da mulher, na construção da aceitação da gravidez e da maternidade.

Estes resultados parecem também indicar que a percepção de apoio social é um importante factor na avaliação da relação com a mãe, o que poderá significar simplesmente que a relação com a mãe é central na percepção de apoio na gravidez. Actualmente, tem-se vindo a perder o contacto, as vivências e a proximidade com as mulheres mais velhas (mães, 
avós, tias, vizinhas), portadoras e transmissoras de um envolvimento e sabedoria, antes muito valorizados, que provinham da própria experiência. Esta rede familiar e social tecida à volta da grávida conferia-lhe protecção e suporte durante as várias fases da gravidez, assegurando também os cuidados do período pós-parto, em que a mulher era quase tão protegida quanto o recém-nascido (Nascimento, 2003). Mas a mãe continua, ainda assim, a ser um recurso de apoio emocional e instrumental privilegiado. De facto, os pais / avós têm ainda, na nossa sociedade, uma importante função de suporte e também pedagógica no nascimento de um bebé, no sentido de "ajudar os filhos a ser pais" (Canavarro, 2001).

Análise de Correlações - Vivência da Gravidez e Relação Mãe-Bebé

Quadro 2: Correlações entre os factores

\begin{tabular}{l|c|c|c|c|c|c}
\hline \multirow{2}{*}{ Factores } & \multicolumn{3}{|c|}{ QAG } & \multicolumn{2}{c|}{ MFA } & $\boldsymbol{\alpha}$ \\
\cline { 2 - 6 } 1. Vivência do Corpo Grávido & 1 & 2 & 3 & 4 & 5 & \\
2. Relação com a Mãe & 1 & & & & & 0,86 \\
3. Mudança Pessoal na Gravidez & $0,259^{* *}$ & 1 & & & & 0,87 \\
4. Envolvimento Emocional com o Bebé & - & - & 1 & & & 0,85 \\
5. Construção da Identidade Materna & $0,473^{* *}$ & $0,280^{* *}$ & $0,254^{* *}$ & 1 & & 0,79 \\
& $0,464^{* *}$ & $0,278^{* *}$ & - & $0,498^{* *}$ & 1 & 0,78 \\
\hline
\end{tabular}

Correlação entre as dimensões da Relação Mãe-Bebé (MFA) - o

"Envolvimento Emocional com o Bebé" (MFA) e a "Construção da Identidade Materna"

Tal como esperávamos, estas duas dimensões da Relação Mãe-Bebé estão relacionadas $(r=0,498, p>0,001)$, indo, portanto, ao encontro das nossas hipóteses iniciais que valorizavam uma estreita ligação entre estes dois processos / tarefas psicológicas.

Correlação entre as dimensões da Relação Mãe-Bebé (MFA) e a "Relação com a Mãe"

A análise das correlações entre as dimensões evidenciou também uma correlação positiva (ainda que fraca) entre a relação com a mãe e ambas as tarefas psicológicas da gravidez, mas não especificamente com a Construção da Identidade Materna. Assim, a correlação da "Relação com a Mãe" é de 0,280 com o factor "Envolvimento Emocional com o Bebé" e de 0,278 com o factor "Construção da Identidade Materna", reflectindo, ainda assim, de forma significativa a ligação entre a relação com a própria mãe e a constru- 
ção da relação com o bebé na gravidez (que poderá remeter para os processos de intergeracionalidade na construção das relações entre pais e filhos).

Correlação entre as dimensões da Relação Mãe-Bebé (MFA) e a "Mudança Pessoal com a Gravidez"

A análise das correlações evidenciou ainda uma correlação positiva fraca entre a "Mudança Pessoal com a Gravidez" e o "Envolvimento Emocional com o Bebé" $(r=0,254)$, mas não com a "Construção da Identidade Materna". Seria de esperar que este factor estivesse mais associado à percepção de "Mudança Pessoal com a Gravidez", pela construção da identidade de mãe que envolve uma reorganização profunda da identidade da mulher. No entanto, é com o factor "Envolvimento Emocional com o Bebé" que este factor se correlaciona significativamente, sublinhando o potencial desenvolvimental e transformador desta relação.

Correlação entre as dimensões da Relação Mãe-Bebé (MFA) e a

"Vivência do Corpo Grávido"

$\mathrm{Na}$ análise das correlações, gostaríamos, no entanto, de destacar os valores encontrados para a associação entre a "Vivência do Corpo Grávido" e a Relação Mãe-Bebé (MFA). Assim, aquele factor do QAG evidenciou uma correlação positiva forte, quer com a dimensão do "Envolvimento Emocional com o Bebé" $(r=0,473, p>0,001)$, como com a dimensão da "Construção da Identidade Materna" $(r=0,464, p>0,001)$, enfatizando o papel da vivência corporal na construção da identidade materna e na construção da relação mãe-bebé na gravidez.

Discussão dos Resultados e Implicações para a Intervenção

Propomos aqui uma leitura transversal mais global dos resultados, que proporcione uma reflexão orientada para as suas implicações, em termos da compreensão e da promoção dos processos de funcionamento e desenvolvimento psicológicos nesta transição, que possa proporcionar pistas para a intervenção psicológica na gravidez.

\section{A Vivência do Corpo Grávido}

Esta dimensão refere-se à vivência positiva do corpo grávido que claramente remete para uma identificação com a gravidez e a maternidade, destacando-se o significado atribuído à "barriga grávida" que representa e evidencia a própria gravidez, quer em termos intra-individuais, como em termos interpessoais. Este factor recolhe médias mais elevadas entre as grá- 
vidas primíparas, as grávidas cuja gravidez foi planeada e as que receberam a notícia da gravidez com uma reacção muito feliz e nada preocupada, permitindo associar este factor a um maior envolvimento emocional com a gravidez, reforçando a noção de que essa vivência da gravidez tem como componente psicológico central a forma como é vivenciado o corpo grávido.

Para promover esta aceitação da gravidez e o início do processo de identificação com a maternidade, poder-se-á ajudar a lidar com as alterações corporais que muitas vezes ocorrem desde as primeiras semanas da gravidez, e que poderão ser bastante intensas (como os enjoos, por exemplo). Mais tarde, com o aparecimento da "barriga" a evidenciar a gravidez, as questões em torno da vivência do corpo acentuam-se. A promoção de uma dieta alimentar saudável poderá ser uma forma de controlo do aumento excessivo de peso e de promoção da partilha do self com o bebé.

Ainda em relação à intervenção nas questões da imagem corporal e da relação com o corpo, que atravessam a gravidez, há que antecipar e trabalhar expectativas, ansiedades e dificuldades relativas ao corpo "pós-parto", pois muitas grávidas apresentam uma grande preocupação com eventuais alterações permanentes no seu peso e formas corporais. Umas poderão esperar alterações exageradas, antecipando um futuro desinvestimento no seu corpo; outras poderão alimentar expectativas, eventualmente idealizadas e irrealistas, de que, depois do parto, tudo voltará "ao normal", ao que seria antes da gravidez. Esta questão poderá ser mais ou menos valorizada pela grávida, mas estará sempre presente sob a forma de dúvidas, receios ou ansiedades, podendo constituir um ponto de partida para, na intervenção psicológica, explorar a forma como a grávida está a lidar com a própria mudança pessoal da gravidez e da maternidade. O psicólogo poderá ainda trabalhar estas questões, preparando esse pós-parto e intervindo simultaneamente na relação mãe-bebé e na qualidade da vivência da gravidez, ao promover comportamentos de cuidado do corpo grávido (como a prevenção de estrias pela aplicação de cremes próprios, a prática de exercício físico ou os cuidados com a pele e o cabelo que eventualmente tenham ficado afectados pelas inevitáveis alterações hormonais).

Assim, se, por um lado, o "gostar" do bebé deverá manifestar-se através de uma atitude construtiva de cuidar do corpo, por outro lado, não podemos esquecer que, em períodos mais sensíveis como a gravidez, podem emergir elementos de uma relação negativa com o corpo, anteriores à própria gravidez. Assim, a intervenção neste domínio deverá envolver a avaliação da história desenvolvimental da relação com o corpo, no sentido da intencionalização de oportunidades que permitam construir uma forma mais adaptativa e satisfatória de vivência do corpo. 


\section{A Relação com a Mãe}

Esta dimensão, relativa à qualidade do laço emocional com a mãe, apresenta valores mais elevados nas grávidas cuja gravidez foi planeada e recebida com uma reacção muito feliz e nada preocupada, e nas que sentem ter muito apoio social.

Os resultados parecem reflectir a importância da relação com a mãe na vivência da decisão de engravidar, mas, em análises futuras, deverá ser considerado o tipo de relação de vinculação construído com a mãe para uma melhor compreensão dos processos psicológicos que poderão estar na base destas associações. Poderemos colocar a hipótese de que, no caso de uma vinculação segura, a mãe constituir-se-á como "base segura" para enfrentar uma situação difícil, como a que poderá ser colocada por uma gravidez não planeada. Por outro lado, esta situação, pela crise no sistema pessoal que envolve, poderá também constituir uma oportunidade de reconstruir a qualidade desta relação, pois uma mãe que se constitua como figura de apoio, transmitindo segurança nestas circunstâncias (mesmo que não o tivesse feito no passado), poderá proporcionar uma reconstrução desta relação mãe-filha, em termos de uma vinculação mais segura do que foi anteriormente.

De qualquer forma, sabemos que a mãe continua a ser um apoio (emocional e instrumental) fundamental na adaptação às mudanças da maternidade: na génese da depressão pós-parto tem, aliás, importância significativa a ausência de factores de protecção materna, nomeadamente a ausência de suporte familiar (Crockenberg \& McCluskey, 1986).

Não podemos, no entanto, esquecer que, por vezes, a par deste apoio, pode surgir alguma confusão entre as gerações sobre os papéis a desempenhar: estes papéis devem ser, no entanto, bem diferenciados e esta situação deverá ser breve e transitória, pelo que cabe também à mulher (eventualmente apoiada pela intervenção psicoterapêutica) (re)negociar esta nova forma de equilíbrio entre apoio e autonomia face aos pais (Canavarro, 2001).

\section{A Percepção de Mudança Pessoal com a Gravidez}

Verificamos que esta dimensão da vivência psicológica da gravidez é influenciada quer por factores associados ao próprio acontecimento de vida (como a paridade ou a percepção de gravidez de risco), quer pelos factores relacionais e contextuais que a enquadram (como o estado civil), pelo que apresentam valores mais elevados de percepção de mudança pessoal, com a gravidez, as grávidas primíparas, as solteiras, as que se sentiram preocupadas com a notícia da gravidez e as que referem uma gravidez de risco. Estes resultados permitem-nos confirmar que este factor é sensível às circunstâncias psicossociais que transformam a gravidez num maior desafio ao sistema pessoal. De facto, é de esperar que uma grávida primí- 
para enfrente um maior desafio desenvolvimental, decorrente das profundas alterações que esta transição implica em toda a sua realidade intra, inter e extrapessoal. A intervenção psicológica na gravidez deve optimizar a oportunidade de mudança proporcionada pela gravidez. No entanto, a forma como as "nossas" participantes perceberam o factor "Mudança Pessoal com a Gravidez" indicia que é atribuída uma significação negativa a esta mudança. Assim, sem nos esquecermos que, como qualquer transição, a primeira gravidez envolve uma crise no sistema pessoal (e respectivo stresse associado), é possível ajudar as grávidas a lidar com esta crise, reenquadrando estes conceitos numa perspectiva integradora que atenda à função desenvolvimental do desequilíbrio psicológico provocado por um acontecimento de vida tão transformador como a gravidez. Assim, a gravidez não deve ser apenas vista como uma ocasião de stresse, mas como uma transição desenvolvimental que exige uma mudança; e a consulta psicológica na gravidez deverá privilegiar a promoção do desenvolvimento psicossocial da grávida, em termos de objectivos de intervenção.

Este impacto da gravidez na vida da mulher parece variar também com a sua situação conjugal, apresentando valores mais elevados as grávidas solteiras que parecem também sentir, assim, um maior impacto da mudança associada à gravidez nas suas vidas. Gostaríamos, ainda, de enfatizar o papel da relação conjugal na resolução desta transição desenvolvimental. De facto, a decisão da gravidez continua a ser vivenciada maioritariamente no contexto de uma relação conjugal, sendo o significado de uma gravidez, em grande parte, uma construção do casal (Fischer et al., 1999). Assim, a forma como ela é experienciada depende muito da qualidade desta relação. Mas há que ter presente na intervenção que, embora durante este período o cônjuge seja habitualmente considerado como a principal fonte de suporte, se verifica uma diminuição da satisfação conjugal (Richardson, 1983). Assim, é importante explorar alterações na dinâmica conjugal e eventuais problemas conjugais, pois a gravidez envolve também um nível de stresse acrescido, podendo suscitar dificuldades específicas. Muitas futuras mães sentem que o companheiro não está suficientemente envolvido com a gravidez, sentindo-se frustradas e pouco apoiadas; os futuros pais também se podem ressentir da labilidade e da irritabilidade da companheira; pode também ser difícil conciliar as diferentes perspectivas sobre a gravidez e a parentalidade. Como em outras transições, a capacidade de falar abertamente de sentimentos positivos e negativos e a capacidade de antecipar áreas problemáticas e suas soluções podem proteger o casal de um maior stresse.

Uma área que é pertinente explorar também neste domínio prende-se com a vivência da sexualidade na gravidez. Muitas são as dúvidas e as dificuldades sexuais que podem surgir neste período e, de facto, estas questões nem sempre são abordadas pelos técnicos de saúde. Mesmo quando isso 
acontece, é normalmente em termos biomédicos que poderão não ser suficientes para lidar com a complexidade que caracteriza a sexualidade enquanto campo atravessado por questões físicas, mas também emocionais, relacionais e culturais. Importante será também antecipar e preparar com o casal as alterações que o nascimento do bebé implicará necessariamente no relacionamento conjugal. Neste sentido, é pertinente explorar a possível idealização desta mudança e preparar as mudanças da relação conjugal no plano afectivo, da rotina diária e do relacionamento sexual, envolvendo sempre que possível o próprio "pai grávido" neste processo de intervenção.

\section{Relação com o Bebé}

É na medida em que se reconhece a continuidade entre a relação mãe-bebé, no período pré e pós-natal, que se sublinha a importância da intervenção psicológica na gravidez como intervenção precoce para a prevenção de dificuldades relacionais posteriores. Assim, a intervenção na relação mãe-bebé é possível e faz sentido desde a gravidez. Mas como promover a qualidade desta relação mãe-bebé in utero? De um modo geral, trata-se de incentivar a representação e a comunicação relativa ao bebé, trata-se de dar espaço para a crescente preocupação com o bebé e com o seu bem-estar, envolvendo a grávida na descrição e personalização do seu bebé a partir das suas fantasias e sonhos, mas também da percepção dos movimentos fetais que, ao ganharem significado, se tornam elementos reais de interacção, e da vivência dos momentos ecográficos e das tocografias que deverão ser também intencionalizados em termos da promoção da relação mãe-filho.

\section{A Vivência do Corpo e a Relação Mãe-Bebé na Gravidez}

De entre os resultados apresentados, destacamos a associação encontrada entre a "Vivência do Corpo Grávido" (QAG) e ambos os Factores da Relação Mãe-Bebé (MFA), numa correlação positiva moderada, quer com a dimensão do "Envolvimento Emocional com o Bebé", como com a dimensão da "Construção da Identidade Materna", sugerindo que a vivência do corpo está relacionada tanto no envolvimento emocional com o bebé (factor 1) como na aquisição do papel de mãe (factor 2), enfatizando a importância da vivência do corpo no processo de "tornar-se" mãe, i.e., de desenvolvimento psicológico e mudança da identidade da mulher, em que é através do corpo que a mulher se vai sentindo e vendo como diferente e, paralelamente, no processo de se relacionar com o bebé, pois é através do corpo que a grávida vai sentindo e interagindo com o bebé. Esta associação remete, portanto, para a ligação estreita entre os processos psicológicos de construção da identidade de mãe e de relação com o bebé e toda a vivência 
e identificação com o "novo" corpo grávido, que parece, assim, poder traduzir o grau de ajustamento à gravidez e de resolução das tarefas desenvolvimentais em torno das quais o desenvolvimento psicológico da transição para a parentalidade ocorre. Por outro lado (tendo em conta que se trata de uma correlação), estes valores também sugerem que uma vivência mais positiva do novo papel de mãe e de todo o processo de relação com o bebé está relacionado com uma maior identificação com o corpo grávido. Assim, uma mulher grávida mais envolvida com o seu bebé e com o seu próprio papel de mãe parece ter também uma relação mais positiva com o seu corpo. Esta associação será naturalmente bidireccional, sendo que uma melhor vivência do "novo" corpo contribuirá para as tarefas psicológicas da gravidez e a melhor adaptação à gravidez contribuirá, também, para uma vivência do corpo grávido mais positiva. Assim, poder-se-á trazer o "corpo vivido", ou a forma como a grávida está a vivenciar o seu "novo" corpo e a sua nova corporeidade, para a intervenção psicoterapêutica junto da grávida, quer como instrumento útil e primeiro de avaliação clínica da forma como esse processo de desenvolvimento está (ou não está) a decorrer, quer como alvo de intervenção, pois, promovendo-se a vivência do "corpo grávido", estaremos a promover também a identificação com a própria gravidez e a maternidade, através da construção da relação com o bebé, ainda na fase intra-uterina.

De salientar que estes resultados vão ao encontro das formulações que fundamentaram o presente estudo, no sentido de conceber e testar o papel desta vivência no desenvolvimento e funcionamento psicológico, nomeadamente na resolução das tarefas desenvolvimentais específicas da gravidez. Estes resultados, ao evidenciarem uma estreita ligação entre aspectos mais relacionais e de desenvolvimento da identidade e as questões relativas à vivência do corpo, colocam o corpo além da concepção mais tradicional do corpo centrada na imagem corporal e respectivo grau de satisfação / insatisfação ${ }^{5}$, afirmando-a, deste modo, no centro de processos de funcionamento e desenvolvimento psicológicos tão avassaladores e importantes como a construção da relação mãe-filho e a transição para a maternidade.

\footnotetext{
${ }^{5}$ A investigação sobre a Imagem Corporal tem valorizado os aspectos avaliativos - de cariz mais cognitivo ou mais afectivo - da relação com o corpo, normalmente com uma conotação negativa que enfatiza percepções e comportamento desajustados, especialmente no contexto das perturbações alimentares.
} 


\section{Conclusão}

A gravidez é um momento crítico em termos de intervenção, pois a natureza da crise desenvolvimental torna a mulher especialmente aberta à mudança, reorganização e transformação. Além disso, é um período em que a mulher está sujeita a um regime organizado de cuidados de saúde, para os quais, na maior parte das vezes, está motivada e desperta. No entanto, é também um momento em que a experiência emocional da mulher pode ser dominada pela depressão, a ansiedade, a somatização ou o desinvestimento emocional, antecipando uma gravidez complicada e dificuldades na relação mãe-bebé. Assim, os sinais de dificuldade na adaptação à gravidez devem ser encarados com preocupação pelos técnicos envolvidos no acompanhamento da gravidez devendo a intervenção psicológica ser proposta como parte integrante de todo o processo de vigilância / acompanhamento da gravidez no sistema de saúde que o enquadra. Assim como é inquestionável a importância das condições médicas e nutricionais para a saúde materno-infantil, não podemos ignorar a importância que o contexto emocional e relacional também assume para a qualidade do desenvolvimento do novo ser, bem como para a adaptação da mulher à gravidez e à maternidade, com implicações, por exemplo, em termos da depressão pós-parto.

\section{Referências}

Canavarro, M. C. (2001). Gravidez e maternidade: Representações e tarefas de desenvolvimento. In M. C. Canavarro (Ed.), Psicologia da gravidez e da maternidade. Coimbra: Quarteto Editora.

Condon, J. T., \& Corklindale, C. (1997). The correlates of antenatal attachment in pregnant women. British Journal of Medical Psychology, 70, 359-72.

Cohen, L. J., \& Slade, A. (2000). The psychology and the psychopathology of pregnancy: Reorganization and transformation. In C. H. Jr. Zeanah (Ed.), Handbook of infant mental health ( $2^{\text {nd }}$ ed., pp. 20-36). Nova Iorque: The Guilford Press.

Colman, L. L., \& Colman, A. D. (1994). Gravidez: A experiência psicológica. Lisboa: Colibri. (Ed. Original, 1991).

Cranley, M. S. (1981). Development of a tool for the measurement of maternal attachment during pregnancy. Nursing Research, 30 (5), 281-4.

Crockenberg, S., \& McCluskey, K. (1986). Change in maternal behavior during the baby's first year of life. Child Development, 57 (3), 746-753.

Fischer, R. C., Stanford, J. B., Jameson, P. \& Dewitt, M. J. (1999). Exploring the concepts of intended, planned and wanted pregnancy. Journal of Family Practice, 48 (2), 117-122. 
Fonagy, P., Steele, H., \& Steele, M. (1991). Maternal representations of attachment during pregnancy predict the organization of infant-mother attachment at one year of age. Child Development, 62, 891-905.

Lee, R. E. (1995). Women look at their experience of pregnancy. Infant Mental Health Journal, 16 (3), 192-205.

Meireles, A., \& Costa, M. E. (2004). Body experience and mother-child relationship in pregnant women (no prelo).

Meireles, A., \& Costa, M. E. (2004). Construção e validação de um questionário de avaliação da vivência da gravidez (no prelo).

Mendes, I. M. (2002). Ligação materno-fetal: Contributo para o estudo de factores associados ao seu desenvolvimento. Coimbra: Quarteto Editora.

Mikulincer, M., \& Florian, V. (1999). Maternal-fetal bonding, coping strategies and mental health during pregnancy: The contribution of attachment style. Journal of Social and Clinical Psychology, 18 (3), 255-276.

Nascimento, M. J. (2003). Preparar o nascimento. Análise Psicológica, 1 (21), 47 -51 .

Ruble, D. N., Fleming, A S., Stangor, C., Brooks-Gunn, J., Fitzmaurice, G., \& Deutsch, F. (1990). Transition to motherhood and the self: Measurement, stability and change. Journal of Personality and Social Psychology, 58 (3), 450-63.

Siddiqui, A., Haeggloef, B., \& Eisemann, M. (2000). Own memories of upbringing as a determinant of prenatal attachment in expectant women. Journal of Reproductive and Infant Psychology, 18 (1), 67-74.

Smith, J. A. (1999). Towards a relational self: Social engagement during pregnancy and psychological preparation for motherhood. British Journal of Social Psychology, 38, 409-26.

Xavier, M. R. (2000). Estatuto de risco das crianças expostas a substâncias ilícitas durante a gestação. Dissertação de Doutoramento não publicada. Porto: Instituto de Ciências Biomédicas Abel Salazar da Universidade do Porto. 